\title{
Results of a Genome-Wide Genetic Screen for Panic Disorder
}

\author{
J.A. Knowles, ${ }^{1,3 *}$ A.J. Fyer, ${ }^{1}$ V.J. Vieland, ${ }^{5}$ M.M. Weissman, ${ }^{1}$ S.E. Hodge, ${ }^{1,4}$ G.A. Heiman, ${ }^{1}$ \\ F. Haghighi, ${ }^{2}$ G.M. de Jesus, ${ }^{1}$ H. Rassnick, ${ }^{1}$ X. Preud'homme-Rivelli, ${ }^{1}$ T. Austin, ${ }^{2}$ J. Cunjak, ${ }^{1}$ \\ S. Mick, ${ }^{1}$ L.D. Fine, ${ }^{1}$ K.A. Woodley, ${ }^{1}$ K. Das, ${ }^{1}$ W. Maier, ${ }^{6}$ P.B. Adams, ${ }^{1}$ N.B. Freimer, ${ }^{7}$ D.F. ${ }^{K}$ lein, ${ }^{1}$ and \\ T.C. Gilliam ${ }^{1,2,3}$ \\ ${ }^{1}$ Department of Psychiatry, College of Physicians and Surgeons at Columbia University and New York State \\ Psychiatric Institute, New York, New York \\ ${ }^{2}$ Department of Genetics \& Development, College of Physicians and Surgeons at Columbia University, \\ New York, New York \\ ${ }^{3}$ Columbia Genome Center, College of Physicians and Surgeons at Columbia University, New York, New York \\ ${ }^{4}$ Division of Biostatistics, School of Public Health, Columbia University, New York, New York \\ ${ }^{5}$ Department of Psychiatry and Preventive Medicine \& Environmental Health, University of Iowa College of Medicine, \\ Iowa City, Iowa \\ ${ }^{6}$ Rheinische Friedrich-Wilhelms-Universitaet, Department of Psychiatry, Bonn, Germany \\ ${ }^{7}$ Center for Neurobiology and Psychiatry, Department of Psychiatry, and Programs in Genetics and Biomedical \\ Sciences, UCSF, San Francisco, California
}

Panic disorder is characterized by spontaneous and recurrent panic attacks, often accompanied by agoraphobia. The results of family, twin, and segregation studies suggest a genetic role in the etiology of the illness. We have genotyped up to 23 families that have a high density of panic disorder with 540 microsatellite DNA markers in a first-pass genomic screen. The thirteen best families (ELOD > 6.0 under the dominant genetic model) have been genotyped with an ordered set of markers encompassing all the autosomes, at an average marker density of $11 \mathrm{cM}$. Over 110,000 genotypes have been generated on the whole set of families, and the data have been analyzed under both a dominant and a recessive model, and with the program SIBPAIR.

No lod scores exceed 2.0 for either parametric model. Two markers give lod scores over 1.0 under the dominant model (chromosomes $1 p$ and 20p), and four do under the

Contract grant sponsor: NIMH; Contract grant numbers MH28274, MH37592, MH30906, 5-T32-18870, MH00084-K21, MH52841, DK-31813, MH-48858; Contract grant sponsor: W.M. Keck Foundation; Contract grant sponsor: NIH; Contract grant number: HG00462; Contract grant sponsor: NARSAD; Contract grant sponsor: Pfizer, Inc.

J.A.K., M.M.W., A.J.F., S.E.H., V.J.V., and J.C.G. contributed equally to this work.

*Correspondence to: Dr. J.A. Knowles, New York State Psychiatric Institute, 722 W. 168th St., Unit \#58, New York, NY 10032. E-mail: jak8@columbia.edu

Received 9 July 1997; Revised 18 September 1997 recessive model $(7 \mathrm{p}, 17 \mathrm{p}, 20 \mathrm{q}$, and $\mathrm{X} / \mathrm{Y})$. One of these (20p) may be particularly promising. Analysis with SIBPAIR yielded $P$ values equivalent to a lod score of 1.0 or greater (i.e., $P<.016$, one-sided, uncorrected for multiple tests) for 11 marker loci $(2,7 p, 8 p$, 8q, 9p, 11q, 12q, 16p, 20p and 20q). Am. J. Med. Genet. (Neuropsychiatr. Genet.) 81: 139-147, 1998. ๑ 1998 Wiley-Liss, Inc.

KEY WORDS: complex genetic disorder; psychiatric genetics; genome screen; chromosome 20

\section{INTRODUCTION}

There is evidence that panic disorder, which has a lifetime prevalence of between $1 \%$ and $2 \%$ across different cultures [Weissman et al., 1997], may be genetically transmitted in a significant proportion of cases. Family studies of panic disorder using RDC, DSM-III, or DSM-III-R diagnostic criteria have consistently found a higher lifetime prevalence of the disorder in the first-degree relatives of probands (17-25\%), than in the first-degree relatives of controls (1.8-4.2\%) [Crowe et al., 1983; Harris et al., 1983; Noyes et al., 1986; Hopper et al., 1990; Maier et al., 1993; Weissman et al., 1993]. The median relative risk to first-degree relatives is about 8-fold when only the DSM-III, or DSM-III-R, studies are considered [Knowles and Weissman, 1995]. The relative risk to first-degree relatives is over twenty times higher if the age-of-onset of the panic disorder probands is less than 20 years [Goldstein et al., 1997]. 
Small twin studies of panic disorder by Torgersen have found concordance rates of $22-31 \%$ for MZ twins and 0\% for DZ twins [Torgersen, 1983, 1990]. In an enlarged sample, the same group, using DSM-III-R criteria, found concordance rates of $25 \%$ for MZ twins and 10\% for DZ twins [Skre et al., 1993]. A large population-based twin study of panic disorder in women found a $24 \% \mathrm{MZ}$ concordance and $11 \% \mathrm{DZ}$ concordance using a "narrow clinicians" diagnosis [Kendler et al., 1993]. The estimate of narrow-sense (additive) heritability of panic disorder using this diagnosis was $46 \%$. This is similar to what has been observed for the other anxiety disorders [Kendler et al., 1992, 1995; Lyons et al., 1993].

Some segregation analyses have suggested the involvement of a major gene in the etiology of panic disorder [Pauls et al., 1980; Crowe et al., 1983]. More specifically, Vieland and coworkers, in a study of 30 systematically ascertained two- and three-generation pedigrees whose probands met DSM-III criteria for panic disorder, but not major depression, found equal support for both recessive and dominant genetic models [Vieland et al., 1993b]. This result has been replicated in an independent sample of 126 families ascertained for DSM-III-R panic disorder [Vieland et al., 1996]. These studies also estimated that a large number of the panic disorder cases in the general population are likely to be phenocopies [Vieland et al., 1993; Vieland et al., 1996]. However, in a linkage study, families are usually selected for the presence of multiple affected individuals, so the population phenocopy rate may not be applicable.

Crowe and colleagues tested 26 families segregating panic disorder for linkage to 29 polymorphic blood group antigens and found a suggestion of linkage to the $\alpha$-haptoglobin locus [Crowe et al., 1987b]. Subsequently this locus was excluded by testing of additional families with DNA markers [Crowe et al., 1990]. The candidate genes pro-opiomelanocortin [Crowe et al., 1987a], tyrosine hydroxylase [Mutchler et al., 1990], and the adrenergic receptor genes [Wang et al., 1992] have also been excluded in the same set of families. The Cys311 variant of DRD2 receptor [Crawford et al., 1995] and the GABA 11 receptor [Schmidt et al., 1993] have also been examined without finding evidence for a causal gene for panic disorder.

The above linkage studies all used dominant genetic models, yet the results from the segregation analyses cited above do not provide compelling evidence that this is the mode of inheritance of panic disorder. Several studies have shown that the power to detect linkage when the mode of inheritance is incorrectly specified is greatly reduced [Clerget-Darpoux et al., 1986; Greenberg and Hodge, 1989; Vieland et al., 1992a,1993a], particularly when the pedigrees are ascertained for the presence of multiple affected individuals. Therefore, it is advisable to analyze the data under at least one recessive model as well.

Previously, we reported an initial genomic screen for linkage to panic disorder using 250 markers against seven families in an attempt to map genetic loci involved in the disorder [Vieland et al., 1994]. In that report, all DNA markers were analyzed with a domi- nant "definitely affected" model, and seventy-five markers were also analyzed with a recessive "definitely affected" model. In these models, all individuals not diagnosed as "definitely" or "probably" affected with panic disorder were considered "unknown." Fifteen markers had lod scores above one, and one of these had a score over two.

Here we present the results of our complete firstpass genomic screen for panic disorder. We have used 540 microsatellite DNA markers to genotype up to 23 families that have a high density of panic disorder. In addition, we have extended our parametric analytic genetic models to include phenocopies, reduced penetrance, and "unaffected" individuals, and also analyzed our data using SIBPAIR [Satsangi et al., 1996].

\section{SUBJECTS, MATERIALS, AND METHODS Clinical Methods}

We ascertained families from three principal sources: (1) anxiety/phobia clinics, (2) therapists who specialize in the treatment of patients with anxiety disorders, and (3) several anxiety support groups or associations. Families that reported at least three affected relatives in two different generations who were available for interview were asked to participate. Those in which transmission of panic disorder appeared to be unilineal were preferentially asked to participate. None of the pedigrees used for this study came from the pedigrees used for the segregation analyses [Vieland et al., 1993, 1996].

Families that appeared to be potentially informative for linkage were evaluated by direct lifetime diagnostic interview of all consenting members contributing to family informativeness for linkage. Interviews were carried out by specially trained clinician interviewers who underwent rigorous diagnostic training under the supervision of senior clinicians [Fyer et al., 1990; Weissman et al., 1993]. Family members were assessed using the Schedule for Affective Disorders and Schizophrenia-Lifetime Version for Anxiety Disorders (SADS-LA) and SADS-LA Revised [Fyer et al., 1985; Mannuzza et al., 1986]. In addition, the interviewers collected multiple informant family history assessments for each relative and spouse using the FH-RDC [Andreasen et al., 1986] or Family Informant Schedule and Criteria (FISC) [Mannuzza et al., 1985](or modifications of the FISC). The interviewers then wrote detailed narrative reports of the clinical symptomatology for all SADS-LA and FISC evaluations [Mannuzza et al., 1993]. In addition, pertinent medical records were collected. After interview assessments of a family were completed, all diagnostic materials on each family member were compiled and blinded with respect to name and family by a research assistant.

Three senior clinical investigators (MMW, DFK, AJF) then independently diagnosed each individual as to level of affectedness for panic disorder. Any case that had discrepant diagnoses between the clinicians was reviewed at a meeting, additional information was collected if necessary, and a consensus diagnosis was 
made (senior best estimate diagnosis). Detailed clinical procedures will be made available on request to investigators attempting to replicate our findings. Clinicians remained blind to the genotypes of families in the laboratory.

In order to reduce phenotypic heterogeneity, we used well-defined and narrow diagnostic criteria. The diagnostic criteria for level of affectedness were as follows:

Definitely affected. All individuals classified as definite panic disorder had DSM-III-R panic disorder with recurrent spontaneous panic attacks \pm agoraphobia [American Psychiatric Association (APA), 1987]. The duration was required to be more than 4 weeks. Panic disorder had to be present after 13 years of age, and the first onset of panic could not be over 45 years [Robins and Regier, 1991]. We also required evidence of impairment, anticipatory anxiety, or avoidance. Panic symptoms could not be limited to periods during which the subject also suffered from major depressive disorder, or substance abuse. A subject could not be classified as definitely affected if the attacks were thought to be atypical by the three senior clinical investigators (e.g., attacks that met DSM-III-R criteria, but in addition, were characterized by unusual symptoms such as slurred speech or vertigo). Rarely, a case that had not been interviewed could be diagnosed as definitely affected, but only if the best estimators felt that there was sufficiently detailed family history information available from multiple informants.

Probably affected. All individuals who met DSMIII-R criteria, but did not qualify for definitely affected status because either the case met most but not all definitely affected criteria, or the symptoms were not well documented (i.e., not directly interviewed or could not give sufficiently detailed history).

Unaffected. Individuals without any evidence of symptoms of panic or agoraphobia. All cases diagnosed as unaffected were directly interviewed.

Unknown. These cases did not fit into definite, probable, or unaffected. Cases which met criteria for panic disorder only during an episode of major depressive disorder, alcohol or drug abuse, were diagnosed as unknown.

A decision had been made prior to genotyping to trade specificity of diagnosis for potentially reduced power in the genome scan, and hence, a large number of the sample is classified as "unknown" (including many individuals with panic disorder "spectrum"). This has the effect of making the parametric analysis similar to an "affecteds only" analysis.

\section{Genotyping}

Lymphocytes were immortalized by transformation with Epstein-Barr virus [Anderson and Gusella, 1984]. DNA was prepared using a standard phenolchloroform extraction protocol. DNA was also extracted from whole blood, and these samples were used to verify the identity of the lymphoblastoid samples. Oligonucleotide primers for DNA sequences for microsatellite markers were purchased from Research Genetics, or synthesized on an ABI Model 392 DNA synthesizer using DNA sequences obtained from the Genome Data
Base (Baltimore, MD). Fifty ng of DNA were amplified in a $10-\mu l$ reaction that contained $10 \mathrm{mM}$ Tris $-\mathrm{HCl} \mathrm{pH}$ $8.3 @ 25^{\circ} \mathrm{C}, 50 \mathrm{mM} \mathrm{KCl}, 1.55 \mathrm{mM} \mathrm{MgCl} 2,0.25 \mathrm{mM}$ of each dNTP, $9.4 \mathrm{ng}$ of each polymerase chain reaction (PCR) primer (one primer had been radioactively labeled with $\gamma$-ATP-32 using $\mathrm{T}_{4}$ polynucleotide kinase), and 0.1 units of Taq polymerase using touchdown PCR [Don et al., 1991]. The annealing temperature was decreased one degree per cycle from $65^{\circ} \mathrm{C}$ to $55^{\circ} \mathrm{C}\left(93^{\circ} \mathrm{C}\right.$ denaturing), and then $17-20$ additional cycles of $90^{\circ} \mathrm{C}$ denaturing, $55^{\circ} \mathrm{C}$ annealing, and $72^{\circ} \mathrm{C}$ elongation were performed. PCR products were resolved on 6\% PAGEUrea $0.4 \mathrm{~mm}$ sequencing gels. Gels were autoradiographed using Kodak XAR film at room temperature. Genotypes were independently interpreted by two readers who were blind to clinical diagnosis. Consensus readings of the genotypes were entered in LABMAN, a FOXPRO-based genetics laboratory database manager [Adams, 1994]. LABMAN checks for inappropriate genotypes (nonmendelization or too many alleles) and outputs the data in the format required by the LINKAGE programs.

\section{Genetic Analyses}

Parametric linkage analyses were performed using the LINKAGE package (MLINK, HOMOG, LINKMAP) [Lathrop et al., 1985]. Genetic parameters were derived as follows: (1) lifetime penetrance estimates were obtained from segregation analysis [Vieland et al., 1993b] for the dominant and recessive models, respectively, with penetrances for males and females fitted to yield the population prevalence of each sex (2:1 female: male ratio) [Robins and Regier, 1991]; (2) a linear ageof-onset correction was applied, with minimum onset at age 6 and maximum penetrance achieved by age 45 ; (3) phenocopy rates for definitely affected individuals were set such that the ratio of penetrances for gene carriers to penetrances for nongene carriers is approximately 70:1 [Vieland et al., 1993b], and (4) phenocopy rates for probable affecteds were set such that this ratio is approximately 50:1 [Vieland et al., 1993b] (so that probable affecteds give less linkage information than definites). The specific parameters for the models are shown in Table I. Male and female recombination distances were assumed to be equal. Marker allele frequencies were calculated from the married-in individuals of the panic disorder pedigrees [Knowles et al., 1992].

Affected sibpair analysis was performed with the SIBPAIR program from the ANALYZE package [Terwilliger, 1997]. SIBPAIR [Kuokkanen et al., 1996; Satsangi et al., 1996] calculates a likelihood-based test statistic equivalent to a lod score calculated under simple recessive inheritance [Hyer et al., 1991; Knapp et al., 1994], except that several aspects of the data are simplified: extended pedigrees are broken down into nuclear families, which are treated as independent; the parents in each resultant nuclear family are coded as +/D heterozygotes at the disease-predisposing locus, affected children are coded as D/D homozygotes, and unaffected children are treated as having unknown trait locus genotype (in the version of SIBPAIR we used). 
TABLE I. Parameters of the Analysis Models Coded for Input to the LINKAGE Program

Dominant (Disease allele frequency $=0.01$ )

Liability class penetrances by genotype:

\begin{tabular}{lccl}
\hline aa & ab & bb & \\
\cline { 1 - 3 } 0.0128 & 0.0128 & 0.00025 & Definite affecteds \\
0.0128 & 0.0128 & 0.00040 & Probable affecteds \\
0.0800 & 0.0800 & 0.00160 & Females 6-16 years old \\
0.3400 & 0.3400 & 0.00680 & Females 17-35 \\
0.5800 & 0.5800 & 0.01160 & Females 36-44 \\
0.6700 & 0.6700 & 0.01300 & Females 45- \\
0.0400 & 0.0400 & 0.00080 & Males 6-16 years old \\
0.1700 & 0.1700 & 0.00340 & Males 17-35 \\
0.2900 & 0.2900 & 0.00580 & Males 36-44 \\
0.3300 & 0.3300 & 0.00700 & Males 45- \\
Recessive (Disease allele frequency $=$ & $0.2)$ \\
0.0179 & 0.00025 & 0.00025 & Definite affecteds \\
0.0179 & 0.00036 & 0.00036 & Probable affecteds \\
0.1200 & 0.00170 & 0.00170 & Females 6-16 years old \\
0.4800 & 0.00670 & 0.00670 & Females 17-35 \\
0.8100 & 0.01160 & 0.01160 & Females 36-44 \\
0.9300 & 0.01300 & 0.01300 & Females 45- \\
0.0600 & 0.00090 & 0.00090 & Males 6-16 years old \\
0.2400 & 0.00340 & 0.00340 & Males 17-35 \\
0.4100 & 0.00580 & 0.00580 & Males 36-44 \\
0.4700 & 0.00700 & 0.00700 & Males 45- \\
\hline
\end{tabular}

Thus, this statistic provides a different measure of the sharing of marker alleles among affected family members than do the lod score calculations under either of our other two models.

Simulations under the assumption of linkage to determine the power of the pedigrees were calculated using the SLINK program (200 replicates) [Ott, 1989; Weeks et al., 1990]. These were performed using the above genetic models, a recombination fraction $(\theta)$ of 0.01 , and a four-allele marker with equal allele frequencies (PIC 0.75).

\section{Construction of Chromosome Exclusion Graphs}

Lod scores summed over all families were plotted by placing the chromosomal position of each marker on the $\mathrm{x}$-axis and the score for each value of theta (after conversion to $\mathrm{cM}$ ) on the $\mathrm{y}$-axis. Marker positions were obtained from multiple sources [NIH/CEPH Collaborative Mapping Group, 1992; Hazen et al., 1992; Weissenbach et al., 1992; Engelstein et al., 1993; Dubovsky et al., 1995]. When marker positions from different sources had to be integrated, the greatest observed intermarker distance was used. Regions of continuous lod scores less than -2.0 were considered to be excluded under the assumptions of the particular analysis model.

\section{RESULTS}

We have collected 23 families containing multiple individuals affected with panic disorder for a linkage study. The families consist of 368 individuals, of whom 269 were directly interviewed. When the 23 pedigrees were broken down into sibships, we had a total of 12 affected sib pairs, 10 affected sib trios, six affected sib quartets, one sibship with five affected sibs, and one sibship with seven affected sibs. By senior best estimate diagnosis, 102 individuals were definitely affected with panic disorder (28\%), 37 individuals were probably affected (10\%), 39 individuals were unaffected (11\%), and 190 individuals were unknown (51\%) (as defined in Subjects, Materials, and Methods).

We began a first-pass genome search with an ordered set of microsatellite markers using a two-stage strategy. The 16 families available at the beginning of the screen were rank-ordered on the basis of expected lod score per genotyped person for the dominant and recessive models (from SLINK). The 13 most-promising of these families (176 individuals) were chosen for use in the first-stage screen. These families provided $83 \%$ (ELOD 6.09/7.30) and 88\% (ELOD 2.64/3.01) of the expected power of the 16-family sample under the dominant and recessive models, respectively. Markers that yielded lod scores over 1.0 for either of these two genetic models were then genotyped with all available additional families ( 23 families by the end of the study) as a follow-up for the second-stage.

Three hundred ninety-four ordered microsatellite markers were used in the first-stage screen $(11 \mathrm{cM}$ average density). Approximately 48 markers (6\%) gave lod scores over 1.0 for one of the two parametric genetic models for the first 13 families. This percentage is similar to what others have seen in a multistage genome scan [Moises et al., 1995]. When the ten additional families were genotyped, the lod scores for most of these markers dropped significantly. Six markers continue to yield lod scores over 1.0 (two with the dominant model and four with the recessive model). These markers and the corresponding lod scores are listed in Table II.

One of these is tantalizing. Our best marker under the dominant genetic model, D20S27, gives a lod score of 1.5. This marker was brought to our attention by Dr. Ray Crowe because it is positive in his independent sample of panic disorder pedigrees (Ray Crowe, personal communication). Flanking markers did not give significant results (D20S115, $13 \mathrm{cM}$ telomeric, $\mathrm{Z}_{\max }=0.0$; GATA81E09, $3 \mathrm{cM}$ centromeric, $\mathrm{Z}_{\max }=0.43$ $\theta=0.3)$. The best parametric lod score in our genome

TABLE II. Markers That Yield Summed Lod Scores Over 1.0, in Up to 23 Families, Ordered by Genetic Model, Then Location

\begin{tabular}{|c|c|c|c|c|c|c|}
\hline Marker & Locus & Location & No. families & Model & $\mathrm{Zmax}$ & $\theta$ \\
\hline MS165 & D1S164 & 1p35 & 21 & Dom & 1.05 & 0.20 \\
\hline MFD25 & D20S27 & $20 \mathrm{p} 12$ & 21 & Dom & 1.50 & 0.20 \\
\hline MFD20 & D7S435 & 7 & 22 & $\operatorname{Rec}$ & 1.71 & 0.10 \\
\hline GATA64B04 & D17S1303 & 17 & 21 & $\operatorname{Rec}$ & 1.06 & 0.10 \\
\hline IP20M41 & D20S39 & $20 \mathrm{q} 13.3$ & 23 & $\operatorname{Rec}$ & 1.02 & 0.10 \\
\hline GATA2A12 & DXYS218 & $\mathrm{X} / \mathrm{Y}$ & 21 & $\operatorname{Rec}$ & 1.07 & 0.10 \\
\hline
\end{tabular}


scan was observed using a recessive model with marker MFD20 on chromosome $7\left(\mathrm{Z}_{\max }=1.71 \theta=0.1\right)$. The flanking markers are mildly positive, but do not exceed a lod score of 1.0 (D7S516, $5 \mathrm{cM}$ telomeric, $\mathrm{Z}_{\max }=0.51$ $\theta=0.2$; D7S526, $2 \mathrm{cM}$ centromeric, $\mathrm{Z}_{\max }=0.28 \theta=0.2$ ).

The data from all markers were analyzed with HOMOG to test for genetic heterogeneity. Markers that gave lod 2 scores in excess of 1.0 at one value [of $\alpha$ and $\theta$ ] (equal to the proportion of linked families) are listed in Table III. There are three clusters of markers on chromosomes 11q13, $15 q 11$, and $20 q 13$ which are positive for neighboring markers. In no case, however, was there statistically significant support for the hypothesis of heterogeneity as compared to homogeneity.

A SIBPAIR analysis was then run. Eleven markers with $P$-values less than 0.016 , which corresponds to a lod score of 1.0, were found and are listed in Table IV. Two of these markers are the same as those identified using the parametric analyses (MFD20 and IP20M1A). The smallest $P$-value was found for marker Wis2 (D8S161), a marker that was genotyped in only seven families, for technical reasons.

As can be seen in Tables II to IV, no markers gave lod scores that exceeded the threshold (lod score 3.3) suggested for declaring linkage to a complex trait in a genome scan [Lander and Kruglyak, 1995], or the classical threshold of 3.0 [Morton, 1955; Ott, 1991]. One possible conclusion of this finding is that a single homogeneous autosomal dominant locus does not underlie the genetic diathesis to panic disorder. To explore this possibility, the summed lod scores for all families were graphed for each chromosome (data not shown). For most chromosomes there are contiguous negative scores below -2.0 over the entire length. Using the criteria of Morton [1955] and Ott [1991], lod scores below -2.0 are usually taken as evidence of exclusion of linkage. Of course, this is only under the assumptions of the particular genetic model (mode of inheritance, genetic homogeneity, specific parameters for gene frequency, penetrance, phenocopy rate, and marker allele frequencies).

Under the homogeneous recessive model, much less of the genome is covered by contiguous negative lod scores. The high gene frequency and phenocopy rate we used in this model make it less powerful to detect linkage. In addition, our ascertainment scheme (three affected individuals in at least two generations), may have reduced the power to detect a recessive locus (relative to a dominant locus).

The two-point lod scores and chromosome graphs are available as both Powerpoint and Excel files by following the link to the Knowles laboratory at: http://www. nyspi.cpmc.columbia.edu/NYSPI/PIDPT_ME.HTM

\section{DISCUSSION}

We have completed a first-pass genomic screen in an effort to detect genetic factors that increase the risk of developing panic disorder. Using microsatellite markers spanning the 22 autosomes at an average spacing of 11 centimorgans, we were unable to detect definitive proof of linkage using two parametric genetic models and SIBPAIR in up to 23 multiplex families. No markers gave lod scores over 2.0 when the full sample was genotyped.

Six markers gave lod scores between 1.0 and 2.0 (Table II) in the 23 families. For one of these markers, D20S27 (dominant model), Dr. Crowe and colleagues (personal communication) also have positive scores using a similar genetic model. If the lod scores of the two groups are combined for D20S27 (on 20p), the resulting lod scores are close to the level suggested for genomewide significance in a complex disorder [Lander and Kruglyak, 1995]. Thus, it may be that this region contains a gene that influences the likelihood of developing panic disorder. If there is, this gene might not be specific to panic disorder, as positive lod scores have been observed with closely linked markers in a genome scan for bipolar disorder.

Early in the study, one marker IP20M41 (D20S39 on $20 \mathrm{q} 13)$, gave a lod score of 2.6 at $\theta=0.0$ with the recessive model with 16 families. However, the lod score decreased to 1.02 at $\theta=0.10$ when seven additional families were genotyped (Table II). Other markers in the region gave negative scores when all 23 families were genotyped, but some of these still give lod scores greater than 1.0 under the hypothesis of hetero-

TABLE III. Markers That Yield Lod Scores Over 1.0 With a Test for Genetic Heterogeneity (HOMOG), in Up to 23 Families, Ordered by Genetic Model, Then Location

\begin{tabular}{|c|c|c|c|c|c|c|c|}
\hline Marker & Locus & Location & No. families & Model & $\mathrm{Zmax}$ & $\theta$ & $\alpha$ \\
\hline MS165 & D1S164 & $1 \mathrm{p} 35$ & 21 & Dom & 1.06 & 0.20 & 0.95 \\
\hline AFM016yc5 & $\mathrm{D} 2 \mathrm{~S} 110$ & 2 & 20 & Dom & 1.43 & 0.00 & 0.45 \\
\hline AFM256zb5 & D11S937 & $11 q$ & 13 & Dom & 1.14 & 0.00 & 0.25 \\
\hline ML91249 & D11S534 & $11 q 13$ & 10 & Dom & 1.06 & 0.00 & 0.25 \\
\hline JG4 & D11S527 & $11 \mathrm{q} 13.5$ & 7 & Dom & 1.49 & 0.00 & 0.25 \\
\hline GATA32F05 & D12S2078 & 12 & 13 & Dom & 1.21 & 0.00 & 0.45 \\
\hline ACTC & ACTC & $15 q$ & 21 & Dom & 1.72 & 0.00 & 0.25 \\
\hline AFM098yg1 & $\mathrm{D} 15 \mathrm{~S} 117$ & $15 q$ & 13 & Dom & 1.00 & 0.00 & 0.35 \\
\hline ML635 & ACTIN & $15 q 11$ & 7 & Dom & 1.74 & 0.00 & 0.45 \\
\hline MFD25 & D20S27 & $20 p$ & 21 & Dom & 1.50 & 0.20 & 1.00 \\
\hline MFD20 & D7S435 & $7 \mathrm{p} 15$ & 22 & Rec & 1.71 & 0.10 & 1.00 \\
\hline GATA64B04 & D17S1303 & 17 & 21 & $\operatorname{Rec}$ & 1.12 & 0.10 & 0.80 \\
\hline IP20M41 & D20S39 & $20 q 13.3$ & 23 & Rec & 1.07 & 0.00 & 0.70 \\
\hline IP20M1 & D20S60 & $20 \mathrm{q} 13.2$ & 23 & Rec & 1.11 & 0.00 & 0.40 \\
\hline IP20M48 & D20S52 & $20 \mathrm{q} 13.3$ & 16 & $\operatorname{Rec}$ & 1.14 & 0.00 & 0.50 \\
\hline GATA2A12 & DXYS218 & $\mathrm{X} / \mathrm{Y}$ & 21 & $\operatorname{Rec}$ & 1.11 & 0.01 & 0.65 \\
\hline
\end{tabular}


TABLE IV. Markers That Gave Equivalent Lod Scores of Over 1.0 Using SIBPAIR, in Up to 23 Families, Ordered by Location

\begin{tabular}{|c|c|c|c|c|c|c|}
\hline Marker & Locus & Location & No. families & Mean IBD & $P$-value & Equivalent lod score \\
\hline AFM263zh9 & D2S207 & 2 & 21 & 0.62 & 0.0108 & 1.145 \\
\hline MFD20 & D7S435 & 7 & 22 & 0.62 & 0.0156 & 1.008 \\
\hline Wis2 & D8S161 & $8 q$ & 7 & 0.76 & 0.0016 & 1.901 \\
\hline ANK1.PCR & ANK1 & 8p11.2-p12 & 10 & 0.74 & 0.0128 & 1.084 \\
\hline AFM158xf12 & D9S168 & 9p22-p24 & 13 & 0.62 & 0.0107 & 1.150 \\
\hline DRD2.509 & DRD2 & $11 \mathrm{q} 22.2-\mathrm{q} 22.3$ & 7 & 0.73 & 0.0151 & 1.020 \\
\hline PAH.PCR4 & $\mathrm{PAH}$ & $12 \mathrm{q} 22-\mathrm{q} 24.2$ & 13 & 0.60 & 0.0135 & 1.061 \\
\hline AFM249yс5 & D16S423 & $16 \mathrm{p} 13.3$ & 22 & 0.62 & 0.0090 & 1.216 \\
\hline IP20M23A & D20S61 & 20 p12 & 10 & 0.64 & 0.0112 & 1.133 \\
\hline AFM165xh2 & D20S109 & $20 \mathrm{q} 12$ & 16 & 0.62 & 0.0053 & 1.422 \\
\hline IP20M1A & D20S60 & $20 q 13.2$ & 23 & 0.62 & 0.0058 & 1.383 \\
\hline
\end{tabular}

geneity (Table III). Interestingly, one study of bipolar disorder obtained positive lod scores with IP20M41 [Ewald et al., 1995]. Other groups have localized benign familial neonatal convulsions (BFNC) [Leppart et al., 1989] and human low voltage $(\alpha)$ electroencephalogram (LVEEG) in adults [Anokhin et al., 1992; Steinlein et al., 1992] to chromosome $20 q$ by linkage analysis. A recent study of LVEEG in a community sample of 124 individuals found that $82 \%$ of the LVEEG subjects had panic disorder, simple phobia, or generalized anxiety disorder [Enoch et al., 1996]. In addition, 7/19 of the subjects with panic disorder or generalized anxiety disorder had LVEEG [Enoch et al., 1996]. Another study of EEG patterns in panic disorder patients did not find an increase in LVEEG [Abraham and Duffy, 1991]. However, our current data are equivocal with regard to the hypothesis that there is a gene that influences the likelihood of developing panic disorder in the $20 \mathrm{q}$ region.

Most of the remaining mildly positive loci from the parametric analyses are likely to be false positive signals, as approximately eleven scores over 1.0 would be expected to be observed by chance with 540 markers analyzed with two genetic models. The same is probably also true for most of the markers identified in the SIBPAIR analysis. The marker that gave the lowest $P$-value $(P=0.0016)$ using SIBPAIR, Wis2, had a maximum lod score of only 0.23 at $\theta=0.22$ with the recessive model. We expected a higher correlation between the parametric recessive test and the results from SIBPAIR, as the sibpair test should be approximately equivalent to an "affecteds only" recessive analysis with no phenocopies and full penetrance [Hyer et al., 1991; Knapp et al., 1994]. On examination, most of this discrepancy comes from one nuclear family with a large sibship of affected individuals and one affected parent. In the recessive analysis, the affected parent contributes no information (because that parent is homozygous for disease), but in the SIBPAIR analysis the parent is assumed to be heterozygous for disease, and therefore contributes to the analysis. For this marker, there was a greater than expected sharing of alleles transmitted by the affected parent to affected members of the sibship. Given that the genetic model underlying the disease is unknown, and could be quite complex, it is impossible, a priori, to know which analysis model is closer to correct.

Examination of the lod scores from the ordered sets of markers genotyped on each chromosome suggests that most of the genome is unlikely to contain a single homogeneous autosomal dominant locus for panic disorder. This is likely to be true for many of the possible dominant genetic models because of two factors: our model allows for reduced penetrance of gene carriers and for phenocopies, and most of the unaffected individuals are considered to be unknown in the analysis. Both of these factors are likely to reduce the power to detect or exclude linkage (unless they correctly specify the actual genetic model). No conclusions about many other simple genetic models such as homogeneous recessive, locus heterogeneity, or multiple additive genetic loci can be made from our results.

Given our failure to detect definitive evidence of linkage to panic disorder in this sample, it is important to consider why this may have happened. Early segregation studies suggested the effect of a major gene [Pauls et al., 1980; Crowe et al., 1983]. For all 23 families the ELOD scores were 9.43 and 3.58 for the dominant and recessive models, respectively. Under the assumption of genetic heterogeneity in which $50 \%$ of the families are linked, the ELOD score for the 23 families were 2.04 and 0.71 for the two models. Thus, our sample should have been powerful enough to detect a major locus if it was inherited as a simple dominant or recessive, but only under the assumption of locus homogeneity. The failure to detect such a locus implies either: the underlying assumptions of the study are wrong, or that the true genetic structure of the disorder is more complex than originally thought.

The first assumption of our study is that panic disorder in the families that we have collected is genetically transmitted. The initial twin studies of Torgersen [1983, 1990] suggested that panic disorder had a large genetic component, but the larger and methodologically improved study of Kendler et al.[1993] indicates that $30-45 \%$ of the propensity to develop panic disorder is genetic. Thus, it appears clear that, in the general population, panic disorder has a significant genetic component. There is no reason to believe that our multiplex families have less of a genetic predisposition than cases in the general population. Therefore, it is likely that the first assumption of the study is correct.

A second assumption is that there is a strong enough phenotype:genotype correlation of panic disorder to enable us to detect linkage. Alternatively, panic disorder could have a higher rate of concordance in MZ twins as compared to DZ twins, but may not be the actual phenotype that is being genetically transmitted. It may 
only be a correlated phenotype. However, our use of reduced penetrances and nonzero phenocopy rates in the linkage analysis should overcome a reduced phenotype:genotype correlation [Durner et al., 1996]. In addition, we are currently exploring ways to refine the phenotype for linkage analysis using an endophenotype $\left(\mathrm{CO}_{2}\right.$ sensitivity) [Perna et al., 1995a,b, 1996], and segregation of comorbid disorders in our families [Savino et al., 1993; Chen and Dilsaver, 1995; MacKinnon et al., 1997].

If both of these assumptions are correct, then there should be genetic factors that contribute to the predisposition to develop panic disorder (as defined in this study) that could be found. Since we did not definitively detect these loci in this search, the true genetic structure of the disorder is likely to be more complex than the simple autosomal dominant and recessive models we analyzed under.

This complexity could occur at several levels. Each individual locus could be genetically complex. Singlelocus linkage analyses have been shown to be robust to mis-specification of genetic parameters for the detection of linkage (but not the estimation of $\theta$ ) [ClergetDarpoux et al., 1986], and the number of genetic loci [Vieland et al., 1992a,b, 1993a] as long as the basic genetic model (i.e., dominant or recessive) at the linked locus is approximately correct [Greenberg and Hodge, 1989]. What is less clear is how robust these types of genetic models would be if each of the genetic loci for panic disorder were not classically Mendelian. Such loci might be those that are imprinted [Driscoll, 1994; Tycko, 1994], act in a sex-specific fashion as has been demonstrated for alcohol preference in mice [Melo et al., 1996], become disease genes via an expanding trinucleotide repeat mechanism [Ashley and Warren, 1995], or other types of loci that are currently unknown.

Another level of complexity is that multiple loci could be interacting to determine the disease phenotype. In this case, our sample, large as it was, could have insufficient power to detect the effect of each genetic locus. This hypothesis is supported by the observation that Crowe and colleagues (using a sample of similar size) find positive scores for one of the same markers as we do. It may be that a sample larger than the size of our two pedigree collections combined will be required to declare linkage to loci for panic disorder. We are now completing a study of intergroup reliability of diagnosis with Dr. Crowe and are pursuing the linkage analysis of both pedigree collections using a common diagnostic and genetic model.

A final level of genetic complexity could be that there are nonautosomal genetic factors for panic disorder. We have excluded the bulk of the autosomes from carrying a single homogeneous dominant locus for panic disorder (under one model), but have not investigated the possibility of a locus either on the sex chromosomes or in the mitochondrial DNA. Classically, both of these types of inheritance would have a recognizable genetic pattern of inheritance in pedigrees that our families do not exhibit (lack of male-to-male transmission for sexlinked, exclusively maternal inheritance for mitochondrial loci). However, there are sex-linked genetic mod- els that can be constructed that allow the apparent male-to-male transmission we observe. One such model would be an X-linked dominant loci with reduced penetrance and a high population frequency. Under this model, the apparent male-to-male transmission would actually be transmission from a nonpenetrant mother. This genetic model could also provide a basis for the approximately 2:1 female:male prevalence rate of the disorder that has been consistently observed in all cultures that have been studied [Weissman et al., 1997]. Given this possibility, we are planning to scan the sex chromosomes for linkage to panic disorder and analyze under such a model. It is interesting to note that one of our mildly positive scores comes from a marker located in the pseudo-autosomal region (GATA2A12).

In any case, we have completed a first-pass genome scan for panic disorder. From our results we can rule out linkage over more than $95 \%$ of the genetic length of the autosomes, under a homogeneous dominant model with reduced penetrance, and over less than $60 \%$ under a homogeneous recessive model with reduced penetrance. We have also found intriguing possible evidence for linkage with a marker on chromosome 20p under a dominant model. We are currently genotyping successive sets of individuals for markers on the autosomes in an attempt to find loci that exhibit locus heterogeneity, beginning with the regions that are mildly positive in this study.

\section{ACKNOWLEDGMENTS}

We thank all the families that have participated in this study. This study was supported in part by NIMH grants MH28274 (MMW), MH37592, and MH30906 (AJF and DFK), 5-T32-18870 (JAK), MH00084-K21 and MH52841 (VJV), DK-31813 and MH-48858 (SEH). TCG was supported by the W.M. Keck Foundation and NIH grant HG00462. JAK was supported by NARSAD (Windisch Young Investigator) and Pfizer Inc. (Award to New Faculty). The authors acknowledge Mary Guardino from the Freedom from Fear Clinic for recruitment of pedigrees, and Dr. Marco Battaglia for bringing the possible association of LVEEG to our attention. We also acknowledge the contributions of Sarah Benson, Adina Judenberg, and Lynn Martin, in collecting pedigrees and the laboratory technical support of Paul White and Charles DeMesa.

\section{REFERENCES}

Abraham HD, Duffy FH (1991): Computed EEG abnormalities in panic disorder with and without premorbid drug abuse. Biol Psychiatry 29: 687-690.

Adams P (1994): LABMAN and LINKMAN: A data management system specifically designed for genome searches of complex diseases. Genet Epidemiol 11:87-98.

American Psychiatric Association (APA) (1987): "Diagnostic and Statistical Manual of Mental Disorders, Revised Third Edition.” Washington, DC:American Psychiatric Association.

Anderson MA, Gusella JF (1984): The use of cyclosporin A in establishing human EBV-transformed lymphoblastoid cell lines. In Vitro 11:856858 .

Andreasen NC, Rice J Endicott J, Reich T, Coryell W (1986): The family history approach to diagnosis: How useful is it? Arch Gen Psychiatry 43:421-429.

Anokhin A, Steinlein O, Fischer C, Yping M, Vogt P, Schalt E, Vogel F 
(1992): A genetic study of the human low-voltage electroencephalogram. Hum Genet 40:99-112.

Ashley CT, Warren ST (1995): Trinucleotide repeat expansion and human disease. Ann Rev Genet 29:703-728.

Chen Y-W, Dilsaver SC (1995): Comorbidity of panic disorder in bipolar illness: Evidence from the Epidemiologic Catchment Area Survey. Am J Psychiatry 152:280-282.

Clerget-Darpoux F, Bonaïti-Pellié C, Hochez J (1986): Effects of misspecifying genetic parameters in lod score analysis. Biometrics 42:393-399.

Crawford F, Hoyne J, Diaz P, Osborne A, Dorotheo J, Sheehan D, Mullan M (1995): Occurrence of the Cys311 DRD2 variant in a pedigree multiply affected with panic disorder. Am J Med Genet 60:332-334.

Crowe RR, Noyes R, Pauls DL, Slymen D (1983): A family study of panic disorder. Arch Gen Psychiatry 40:1065-1069.

Crowe RR, Noyes R Jr, Persico AM (1987a): Pro-opiomelanocortin (POMC) gene excluded as a cause of panic disorder in a large family. J Affect Disord 12:23-27.

Crowe RR, Noyes R, Jr, Wilson AF, Elston RC, Ward LJ (1987b): A linkage study of panic disorder. Arch Gen Psychiatry 44:933-937.

Crowe RR, Noyes R Jr, Samuelson S, Wesner R, Wilson R (1990): Close linkage between panic disorder and alpha-haptoglobin excluded in 10 families. Arch Gen Psychiatry 47:377-380.

Don RH, Cox PT, Wainwright BJ, Mattick JS (1991): "Touchdown" PCR to circumvent spurious priming during gene amplification. Nucleic Acids Res 19:4008.

Driscoll DJ (1994): Genomic imprinting in humans. Mol Genet Med 4:3777

Dubovsky J, Sheffield VC, Duyk GM, Weber JL (1995): Sets of short tandem repeat polymorphisms for efficient linkage screening of the human genome. Hum Mol Genet 4:449-452.

Durner M, Greenberg DA, Hodge SE (1996): Phenocopies versus genetic heterogeneity: can we use phenocopy frequencies in linkage analysis to compensate for heterogeneity? Hum Hered 46:265-273.

Engelstein M, Hudson TJ, Lane JM, Lee MK, Leverone B, Landes GM Peltonen L, Weber JL, Dracopoli NC (1993): A PCR-based linkage map of human chromosome 1 . Genomics 15:251-258.

Enoch MA, Rohrbaugh JW, Davis EZ, Harris CR, Ellingson RJ, Andreason P, Moore V, Varner JL, Brown GL, Eckardt MJ, Goldman D (1996) Relationship of genetically transmitted alpha EEG traits to anxiety disorders and alcoholism. Am J Med Genet 60:400-408.

Ewald H, Eiberg H, Mors O (1995): A search for genes predisposing to manic depressive illness on chromosome 20. Psychiatric Genet 5:105111.

Fyer AJ, Endicott J, Mannuzza S, Klein DF (1985): Schedule for affective disorders and schizophrenia-lifetime version for anxiety disorders (SADS-LA). (Abstract)

Fyer AJ, Mannuzza S, Gallops S, Martin LY, Aaronson C, Gorman JM, Liebowitz MR, Klein DF (1990): Familial transmission of simple phobias and fears. A preliminary report. Arch Gen Psychiatry 47:252-256.

Goldstein RB, Wickramaratne P, Horwath E, Weissman MM (1997): Familial aggregation and phenomenology of "early" (<20 years) onset panic disorder. Arch Gen Psychiatry 54:271-278.

Greenberg DA, Hodge SE (1989): Linkage analysis under "random" and "genetic" reduced penetrance. Genet Epidemiol 6:259-264.

Harris EL, Noyes R Jr, Crowe RR, Chaudhry DR (1983): Family study of agoraphobia. Report of a pilot study. Arch Gen Psychiatry 40:10611064.

Hazen J, Dubay C, Pankowiak M, Becuwe N, Weissenbach J (1992): A genetic linkage map of human chromosome 20 composed entirely of microsatellite markers. Genomics 12:183-189.

Hopper JL, Judd FK, Derrick PL, Macaskill GT, Burrows GD (1990): A family study of panic disorder: Reanalysis using a regressive logistic model that incorporates a sibship enviroment. Genet Epidemiol 7:151161.

Hyer RN, Julier C, Buckley JD, Trucco M, Rotter J, Spielman R, Barnett A, Bain S, Boitard C, Deschamps I et al. (1991): High-resolution linkage mapping for susceptibility genes in human polygenic disease: Insulin-dependent diabetes mellitus and chromosome 11q. Am J Hum Genet 48:243-257.

Kendler KS, Neale MC, Kessler RC, Heath AC, Eaves LJ (1992): The genetic epidemiology of phobias in women. The interrelationship of agoraphobia, social phobia, situational phobia, and simple phobia. Arch Gen Psychiatry 49:273-281.
Kendler KS, Neale MC, Kessler RC, Heath AC, Eaves LJ (1993): Panic disorder in women: A population-based twin study. Psychol Med 23: 397-406.

Kendler KS, Walters EE, Neale MC, Kessler RC, Heath AC, Eaves LJ (1995): The structure of the genetic and environmental risk factors for six major psychiatric disorders in women. Phobia, generalized anxiety disorder, panic disorder, bulimia, major depression, and alcoholism. Arch Gen Psychiatry 52:374-383.

Knapp M, Seuchter SA, Baur MP (1994): Linkage analysis in nuclear families. 2: Relationship between affected sib-pair tests and lod score analysis. Hum Hered 44:44-51.

Knowles JA, Vieland VJ, Gilliam TC (1992): Perils of gene mapping with microsatellite markers [letter]. Am J Hum Genet 51:905-909.

Knowles JA, Weissman MM (1995) Panic disorder and agoraphobia. In Volume 14, Oldham JM, and Riba MB (eds): "Review of Psychiatry." Washington, DC: American Psychiatric Press, pp 383-404.

Kuokkanen S, Sundvall M, Terwilliger JD, Tienari PJ, Wikstrom J, Holmdahl R, Pettersson U, Peltonen L (1996): A putative vulnerability locus to multiple sclerosis maps to $5 \mathrm{p} 14-\mathrm{p} 12$ in a region syntenic to the murine locus Eae2. Nature Genet 13:477-480.

Lander ES, Kruglyak L (1995): Genetic dissection of complex traits: Guidelines for interpreting and reporting linkage results. Nature Genet 11: 241-247.

Lathrop GM, Lalouel JM, Julier C, Ott J (1985): Multilocus linkage analysis in humans: Detection of linkage and estimation of recombination. Am J Hum Genet 37:482-498.

Leppart M, Anderson VE, Quattlebaum T, Stauffer D, O'Conell P, Lathrop M, Lalouel JM, White R (1989): Benign neonatal convulsions linked to genetic markers on chromosome 20. Nature 337:647-648.

Lyons MJ, Goldberg J, Eisen SA, True W, Tsuang MT, Meyer JM, Henderson WG, (1993): Do genes influence exposure to trauma? A twin study of combat. Am J Med Genet 48:22-27.

MacKinnon DF, McMahon FJ, Simpson SG, McInnis MG, DePaulo JR (1997): Panic disorder with familial bipolar disorder. Biol Psychiatry (in press).

Maier W, Lichtermann D, Minges J, Oehrlein A, Franke P (1993): A controlled family study in panic disorder. J Psychiatric Res 27:Suppl 1: 79-87.

Mannuzza S, Fyer AJ, Endicott J, Klein DF (1985): "Family Informant Schedule and Criteria." New York: Anxiety Disorders Clinic, New York State Psychiatric Institute.

Mannuzza S, Fyer AJ, Klein DF, Endicott J (1986): Schedule for affective disorders and schizophrenia-lifetime version (modified for the study of anxiety disorders): Rational and conceptual development. J Psychiatr Res 20:317-325.

Mannuzza S, Fyer AJ, Klein DF (1993): Assessing psychopathology. Int J Methods Psychiatric Res 3:72.1-72.9.

Melo JA, Shendure J, Pociask K, Silver LM (1996): Identification of sexspecific quantitative trait loci controlling alcohol preference in C57BL/ 6 mice. Nature Genet 13:147-153.

Moises HW, Yang L, Kristbjarnarson H, Wiese C, Byerley W, Macciardi F, Arolt V, Blackwood D, Liu X, Sjogren B et al. (1995): An international two-stage genome-wide search for schizophrenia susceptibility genes. Nature Genet 11:321-324

Morton NE (1955): Sequential tests for the detection of linkage. Am J Hum Genet 7:277-318.

Mutchler K, Crowe RR, Noyes R Jr, Wesner RW (1990): Exclusion of the tyrosine hydroxylase gene in 14 panic disorder pedigrees. Am J Psychiatry 147:1367-1369.

NIH/CEPH Collaborative Mapping Group (1992): A comprehensive genetic linkage map of the human genome. Science 258:67-86.

Noyes R Jr, Crowe RR, Harris EL, Hamra BJ, McChesney CM, Chaudhry DR (1986): Relationship between panic disorder and agoraphobia. A family study. Arch Gen Psychiatry 43:227-232.

Ott J (1989): Statistical properties of the haplotype relative risk. Genet Epidemiol 6:127-130.

Ott J (1991): “Analysis of Human Genetic Linkage.” Baltimore and London:The Johns Hopkins University Press.

Pauls DL, Bucher KD, Crowe RR, Noyes RJ (1980): A genetic study of panic disorder pedigrees. Am J Hum Genet 32:639-644.

Perna G, Bertani A, Arancio C, Ronchi P, Bellodi L (1995a): Laboratory response of patients with panic and obsessive-compulsive disorders to $35 \% \mathrm{CO}_{2}$ challenges. Am J Psychiatry 152:85-89. 
Perna G, Cocchi S, Bertani A, Arancio C, Bellodi, L. (1995b): Sensitivity to $35 \% \mathrm{CO}_{2}$ in healthy first-degree relatives of patients with panic disorder. Am J Psychiatry 152:623-625.

Perna G, Bertani A, Caldirola D, Bellodi L (1996): Family history of panic disorder and hypersensitivity to $\mathrm{CO}_{2}$ in patients with panic disorder. Am J Psychiatry 153:1060-1064.

Robins LN, Regier DA (1991) "Psychiatric Disorders in America: The Epidemiologic Catchment Area Study.” New York: The Free Press.

Satsangi J, Parkes M, Louis E, Hashimoto L, Kato N, Welsh K, Terwilliger JD, Lathrop GM, Bell JI, Jewell DP (1996): Two stage genome-wide search in inflammatory bowel disease provides evidence for susceptibility loci on chromosomes 3, 7 and 12. Nature Genet 14:199-202.

Savino M, Perugi G, Simonini E, Soriani A, Cassano GB, Akiskal HS (1993): Affective comorbidity in panic disorder: Is there a bipolar connection? J Affect Disord 28:155-163.

Schmidt SM, Zoega T, Crowe RR (1993): Excluding linkage between panic disorder and the gamma-aminobutyric acid beta 1 receptor locus in five Icelandic pedigrees. Acta Psychiatr Scand 88:225-228.

Skre I, Torgersen S, Lygren S, Kringlen E (1993): A twin study of DSMIII-R anxiety disorders. Acta Psychiatr Scand 88:85-92.

Steinlein O, Anokhin A, Yping M, Schalt E, Vogel F (1992): Localization of a gene for the human low-voltage EEG on $20 \mathrm{q}$ and genetic heterogeneity. Genomics 12:69-73.

Terwilliger JD (1997): ANALYZE computer program (Abstract).

Torgersen S (1983): Genetic factors in anxiety disorders. Arch Gen Psychiatry 40:1085-1089.

Torgersen S (1990): Comorbidity of major depression and anxiety disorders in twin pairs. Am J Psychiatry 147:1199-1202.

Tycko B (1994): Genomic imprinting: Mechanism and role in human pathology. Am J Pathol 144:431-443.

Vieland VJ, Greenberg DA, Hodge SE (1992a): Adequacy of single-locus approximations for linkage analyses of oligogenetic traits. Genet Epidemiol 9:45-59.
Vieland VJ, Greenberg DA, Hodge SE, Ott J (1992b): Linkage analysis of two-locus diseases under single-locus and two-locus analysis models. Cytogenet Cell Genet 59:145-146.

Vieland VJ, Greenberg DA, Hodge SE (1993a): Adequacy of single-locus approximations for linkage analyses of oligogenic traits: Extension to multigenerational pedigree structures. Hum Hered 43:329-336.

Vieland VJ, Hodge SE, Lish JD, Adams P, Weissman MM (1993b): Segregation analysis of panic disorder. Psychiatric Genet 3:63-71.

Vieland VJ, Knowles J, Fyer AJ et al. (1994): Linkage study of panic disorder: A preliminary report. In Gershon ES, Cloninger CR (eds): "Genetic Approaches to Mental Disorders." Washington, D.C.: American Psychiatric Press, Inc., pp 345-354.

Vieland VJ, Goodman DW, Chapman T, Fyer AJ (1996): New segregation analysis of panic disorder. Am J Med Genet 67:147-153.

Wang ZW, Crowe RR, Noyes RJ (1992): Adrenergic receptor genes as candidate genes for panic disorder: A linkage study. Am J Psychiatry 149: 470-474.

Weeks DE, Ott J, Lathrop GM (1990): SLINK: A general simulation program for linkage analysis. Am J Hum Genet 47:A204 (Abstract).

Weissenbach J, Gyapay G, Dib C, Vignal A, Morissette J, Millasseau P, Vaysseix G, Lathrop M (1992): A second-generation linkage map of the human genome. Nature 359:794-801.

Weissman MM, Wickramaratne P, Adams PB, Lish JD, Horwath E, Charney D, Woods SW, Leeman E, Frosch E (1993): The relationship between panic disorder and major depression. A new family study. Arch Gen Psychiatry 50:767-780.

Weissman MM, Bland RC, Canino GJ, Faravelli C, Greenwald S, Hwu HG, Joyce PR, Karam EG, Lee CK, Lellouch J, Lepine JP, Newman SC, Oakley-Browne MA, Rubio-Stipec M, Wickramaratne PJ, Wittchen HU, Yeh EK. (1997): The cross-national epidemiology of panic disorder: Prevalence, patterns and suicide attempts. Arch Gen Psychiatry 54:305-309. 